OPEN ACCESS

Edited by:

Ron Shaoul,

Rambam Health Care Campus, Israe

Reviewed by:

Yoram Bujanover,

Edmonds Community College,

United States

Francesco Valitutti,

Ospedali Riuniti San Giovanni di Dio e

Ruggi d'Aragona, Italy

*Correspondence:

Peng Huang

huangpengncu@163.com

Specialty section:

This article was submitted to

Pediatric Gastroenterology,

Hepatology and Nutrition,

a section of the journal

Frontiers in Pediatrics

Received: 24 September 2020 Accepted: 18 January 2021

Published: 09 February 2021

Citation:

Ji C, Liu X and Huang P (2021) Carbon Dioxide vs. Air Insufflation for Pediatric Gastrointestinal Endoscopy:

A Systematic Review and Meta-Analysis of Randomized Controlled Trials.

Front. Pediatr. 9:610066. doi: 10.3389/fped.2021.610066

\section{Carbon Dioxide vs. Air Insufflation for Pediatric Gastrointestinal Endoscopy: A Systematic Review and Meta-Analysis of Randomized Controlled Trials}

\author{
Chunwang $\mathrm{Ji}^{1}$, Xue Liu ${ }^{2}$ and Peng Huang ${ }^{3 *}$ \\ ${ }^{1}$ Grade 2017, Queen Mary Institute, Nanchang University, Nanchang, China, ${ }^{2}$ Shandong University of Traditional Chinese \\ Medicine, Jinan, China, ${ }^{3}$ Jiangxi Province Key Laboratory of Preventive Medicine, School of Public Health, Nanchang \\ University, Nanchang, China
}

Background: Carbon dioxide $\left(\mathrm{CO}_{2}\right)$ insufflation during gastrointestinal (Gl) endoscopic procedures has gained popularity in adults. However, its utility in pediatric patients is not known. The current review aimed to compare the efficacy of $\mathrm{CO}_{2}$ vs. air insufflation for $\mathrm{Gl}$ endoscopic procedures in pediatric patients.

Methods: The electronic databases of PubMed, Embase, Scopus, and CENTRAL were searched from the inception of databases to 15th August 2020.

Results: All randomized controlled trials (RCTs) comparing $\mathrm{CO}_{2}$ vs. air insufflation for $\mathrm{Gl}$ endoscopic procedures in pediatric patients were eligible for inclusion. Five RCTs were identified. Pooled analysis of data from 226 patients in the $\mathrm{CO}_{2}$ group and 224 patients in the air group revealed that patients receiving $\mathrm{CO}_{2}$ insufflation were at a lower odds of experiencing postoperative pain as compared to those undergoing the procedure with air (OR: 0.40; 95\% Cl: 0.19, 0.87; $P^{2}=62 \% ; p=0.02$ ). Descriptive analysis indicated no difference in the two groups for abdominal distention after the procedure. Two trials reported elevated $\mathrm{CO}_{2}$ in the study group but without any pulmonary complications. Bloating was reported by two studies and both reported significantly less bloating in the $\mathrm{CO}_{2}$ group.

Conclusion: Our study indicates that the incidence of pain may be reduced with the use of $\mathrm{CO}_{2}$ insufflation in pediatric $\mathrm{Gl}$ endoscopies without a significant risk of adverse events. However, current evidence is from a limited number of trials and not strong to recommend a routine of $\mathrm{CO}_{2}$ in pediatric gastroenterology practice. Further high-quality RCTs are required to supplement current evidence.

Keywords: Carbon dioxide, gastrointestinal pain, children, colonoscopy, endoscopy 


\section{INTRODUCTION}

Endoscopy is a common procedure in a pediatric gastroenterology practice, with current technology permitting examination of all patients from infants to adults. Optimal intestinal distention is extremely essential for proper examination during endoscopy whether it is esophagogastroduodenoscopy (EGD) or colonoscopy (1). Traditionally, air has been used for insufflation of the gastrointestinal (GI) tract. However, owing to its poor intestinal resorption, it frequently leads to post-operative bowel distention and bloating (2). Pain and discomfort after the procedure is frequently attributed to the residual bowel gas (3).

In the 1950s, carbon dioxide $\left(\mathrm{CO}_{2}\right)$ was first proposed as an insufflating agent for adult colonoscopies and rigid sigmoidoscopies (4). Since the absorption rate of $\mathrm{CO}_{2}$ is 160 times that of nitrogen and 13 times that of oxygen, the residual gas after endoscopy with $\mathrm{CO}_{2}$ insufflation is significantly less $(5,6)$. Over the last two decades, several studies have confirmed the efficacy and safety of $\mathrm{CO}_{2}$ insufflation as compared to air in adult patients especially for colonoscopy and enteroscopy. In a 2016 systematic review and meta-analysis, Memon et al. (7) have demonstrated that the use of $\mathrm{CO}_{2}$ insufflation in adult colonoscopies significantly reduced intra-operative abdominal pain with effects lasting up to $24 \mathrm{~h}$. These results are further corroborated by a recent meta-analysis of Rogers et al. (8), who have found that adult patients undergoing colonoscopy with $\mathrm{CO}_{2}$ insufflation have significantly reduced pain scores with less distention, bloating, and flatulence. Aquino et al. (9) in a metaanalysis have demonstrated that the use of $\mathrm{CO}_{2}$ insufflation during enteroscopy significantly reduces pain at 1 and $4 \mathrm{~h}$ after the procedure.

Pediatric patients routinely undergo EGD or colonoscopy as a diagnostic or therapeutic procedure (10-14). However, with continuous research, the indications for EGD or colonoscopy in pediatric patients is constantly evolving. In children, EGD is being increasingly used not only for diagnosis of eosinophilic esophagitis but also for surveillance and to assess disease activity post-treatment (15). On the other hand, with increased accuracy of serological tests, endoscopic investigations can be avoided for patients with celiac disease (16). Despite numerous clinical trials and reviews on the use of $\mathrm{CO}_{2}$ insufflation for endoscopy in adults $(7,9,17,18)$, data concerning pediatric patients is scarce. Over the past few years, studies have evaluated the benefits of $\mathrm{CO}_{2}$ insufflation during GI endoscopy in pediatric patients. However, to the best of our knowledge, no attempt has been made to synthesize data from these studies to provide level-1 evidence on the use of $\mathrm{CO}_{2}$ insufflation for pediatric patients. Therefore, the purpose of this review was to conduct a systematic literature search and pool data comparing the efficacy of $\mathrm{CO}_{2}$ insufflation vs. air insufflation for GI endoscopic procedures in pediatric patients.

\section{MATERIALS AND METHODS}

\section{Search Strategy}

The authors designed and implemented this review adhering to the guidelines of the PRISMA statement (Preferred Reporting
Items for Systematic Reviews and Meta-analyses) (19) and the Cochrane Handbook for Systematic Reviews of Intervention (20), except for protocol registration. The electronic databases of PubMed, Embase, Scopus, and CENTRAL were searched by two reviewers independently. Search limits were from inception of databases to 15th August 2020. For the search, we used a combination of $\mathrm{MeSH}$ terms and free-text keywords. The terms "carbon dioxide," "CO 2 ," "air," "colonoscopy," "endoscopy," "enteroscopy," "insufflation," "pediatric," "children," and "pain” were used in different combinations. The reviewers screened the search results initially by their titles and abstracts for each database. After identifying potentially pertinent articles, full texts of the articles were extracted. Both the reviewers assessed individual articles based on the inclusion and exclusion criteria. Any disagreements were resolved by discussion. After screening, the bibliography of included studies and review articles on the subject were hand searched for any missed references.

\section{Inclusion Criteria}

Only randomized controlled trials (RCTs) were eligible to be included in the review. We further defined the inclusion criteria based on the PICO (Population, Intervention, Comparison, Outcome) framework as follows:- Population: studies conducted on pediatric patients undergoing GI endoscopy. The intervention was to be $\mathrm{CO}_{2}$ insufflation for visualization during the procedure compared (Comparison) to air. Included studies were to report at least one of the following outcomes: pain, abdominal distention, and elevated $\mathrm{EtCO}_{2}$. No language restriction was placed. We excluded studies on adults, non-RCTs, retrospective studies, single-arm studies, and studies not reporting relevant data.

\section{Data Extraction}

After mutual agreement on the inclusion of studies, data were extracted by two reviewers independently. Data regarding authors, publication year, study type, demographic details, body mass index (BMI), sample size, patients with pre-procedural abdominal pain, duration of the procedure, anesthesia protocol, and study outcomes were extracted. The primary outcome of the interest of our analysis was pain after the procedure. The secondary outcomes were abdominal distention and elevated $\mathrm{EtCO}_{2}$. Any other outcomes reported by the included studies were reported also descriptively.

\section{Risk of Bias Assessment}

The Cochrane Collaboration risk assessment tool was used for assessing the quality of included RCTs (20). Two reviewers independently assessed each study. The following seven domains were used for quality assessment: random sequence generation, allocation concealment, blinding of participants and personnel, blinding of outcome assessment, incomplete outcome data, and selective reporting. The study was judged to have a "high," "unclear," or "low" risk of bias for each domain. Any disagreements were resolved by discussion.

\section{Statistical Analysis}

Meta-analysis was conducted in at least three trials reported similar outcomes, otherwise, a descriptive analysis was carried 
out. "Review Manager" (RevMan, version 5.3; Nordic Cochrane Centre [Cochrane Collaboration], Copenhagen, Denmark; 2014) was used for the meta-analysis. Outcome data was fed into meta-analysis software and cross-checked for correctness. Since included studies reported the presence/absence of pain in the postoperative period, we calculated Odds ratios (OR) with 95\% confidence intervals (CI). We used a random-effects model to calculate the pooled effect size for all our analysis.

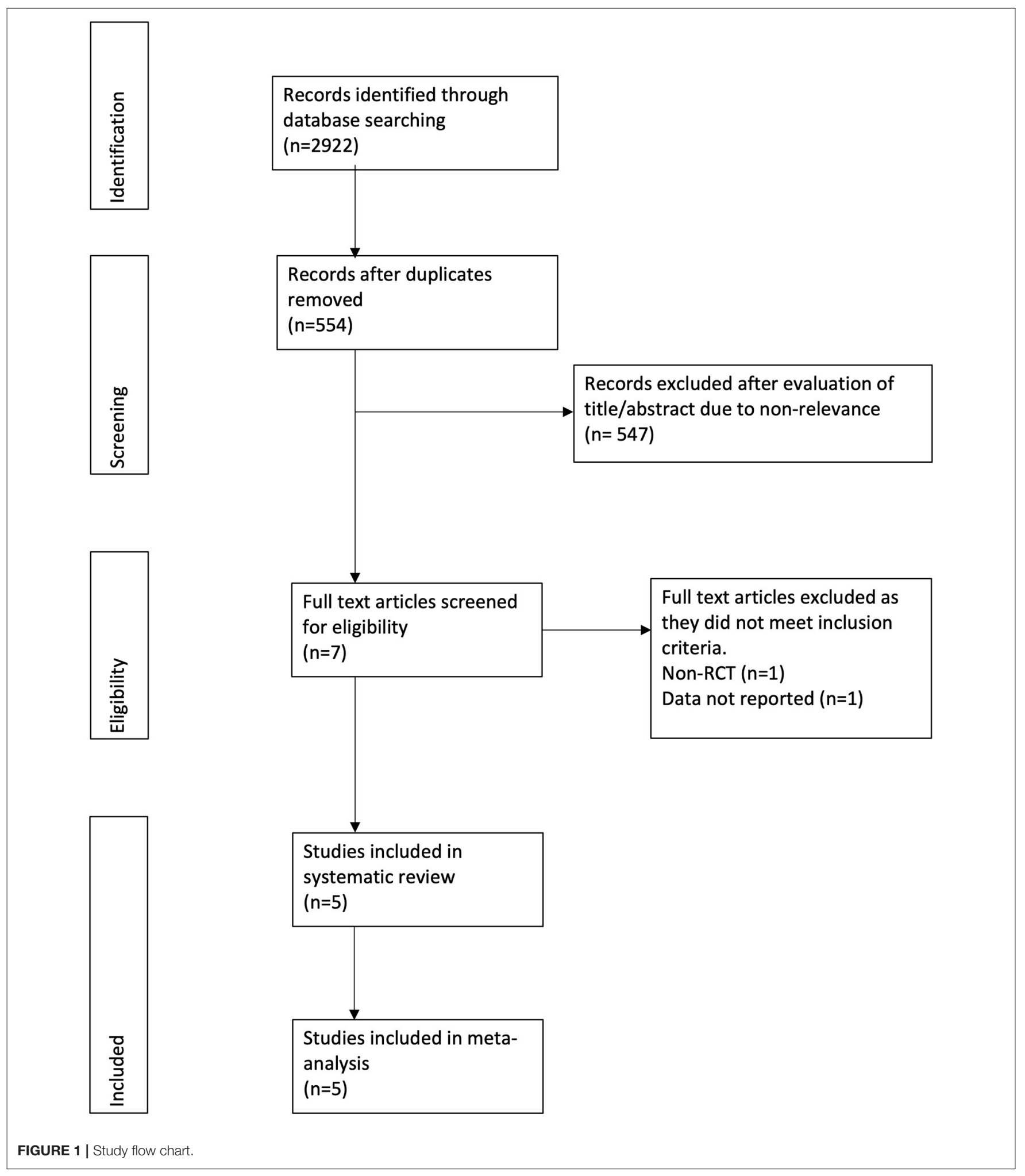


TABLE 1 | Details of included studies.

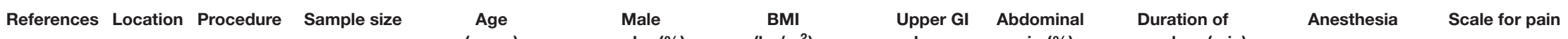
(years) $\quad$ gender $(\%) \quad\left(\mathrm{kg} / \mathrm{m}^{2}\right) \quad$ endoscopy $\quad$ pain $(\%) \quad$ procedure $(\mathrm{min})$

(\%)

\begin{tabular}{|c|c|c|c|c|c|c|c|c|c|c|c|c|c|c|c|c|}
\hline & & & $\mathrm{CO}_{2}$ & Air & $\mathrm{CO}_{2}$ & Air & $\mathrm{CO}_{2}$ & Air & $\mathrm{CO}_{2}$ & Air & $\mathrm{CO}_{2}$ & Air & $\mathrm{CO}_{2}$ & Air & $\mathrm{CO}_{2}$ & Air \\
\hline $\begin{array}{l}\text { Dike et al. } \\
\text { (27) }\end{array}$ & USA & $\begin{array}{l}\text { Upper Gl } \\
\text { endoscopy } \\
\text { and }\end{array}$ & 91 & 89 & $\begin{array}{c}12.8 \\
(1.1-20.4)^{\star}\end{array}$ & $\begin{array}{c}13.7 \\
(1.4-20.8)^{\star}\end{array}$ & 48 & 39 & $\begin{array}{c}0.16 \\
(-4.96,2.61)^{\wedge}\end{array}$ & $\begin{array}{c}-0.03 \\
(-3.79 \\
2.48)\end{array}$ & $48^{\Phi}$ & $49^{\$}$ & 48 & 53 & $N R$ & NR \\
\hline
\end{tabular}

colonoscopy

Dharmara

Colonoscopy

$48 \quad 52$

$13.8 \pm 2.8 \quad 15.5 \pm 3 \quad 54.2 \quad 44.2$

$20.8 \quad 20.6$

6

$-$

$12.8 \quad 24.2$

$28.79 \pm N R \quad 28.17 \pm N R$ Propofol

$(17.1-23.4)^{*}(18-24.4)^{\star}$

Continuous Pain on

propofol infusion FLACC/Faces pain

without advanced scale and GPPP

airway

scale

(Occasionally GA

used)

et al. (26)

induction with

combination of

nitrous oxide,

sevoflurane,

propofol for deep

sedation

Kresz et al. Germany Upper Gl

$13.7 \pm 3.2 \quad 12.7 \pm 2.7 \quad 57.4 \quad 52.9$

$19.5 \pm 3.5 \quad 19 \pm 2.5 \quad 56.4^{\#} 61.8^{\#}$

33.350

$31.3 \pm 13.2 \quad 31.5 \pm 16.7$ Sedation using midazolam and

VAS/Faces pain

and

Colonoscopy

Thornhill et al. USA Colonoscopy

2020

$5-18$

$40 \quad 55$

NR

NR

propofol

VAS

(25)

Upper Gl
endoscopy

and

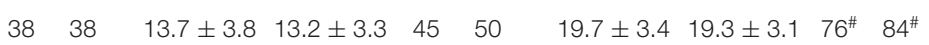

$45 \quad 55 \quad$ NR

NR

GA

analog scale

Homan et al. USA

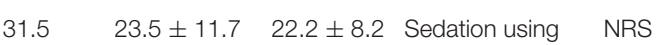

ketamine and

midazolam

RCT, randomized controlled trial; FLACC, face legs activity cry and ability to be consoled; GPPP, global parent perception of pain; VAS, visual analog scale; NRS, numerical rating scale; Gl, gastrointestinal; GA, general anesthesia.

$\wedge_{z}$-score, median (range).

"Median (Interquartile range).

\#All concomitant endoscopies.

\$Exclusive upper Gl endoscopies. 
Heterogeneity was assessed using the $I^{2}$ statistic. $I^{2}$ values of $25-50 \%$ represented low, values of $50-75 \%$ medium, and more than $75 \%$ represented substantial heterogeneity. We also assessed the influence of each study on the pooled OR using a sensitivity analysis. Due to the inclusion of fewer than 10 studies per metaanalysis, funnel plots were not used to assess publication bias.

\section{RESULTS}

The study flow chart is presented in Figure 1. A total of seven articles were assessed of which two were excluded (21, 22). Five studies (23-27) met the inclusion criteria and were included in the review. Details of the included studies are presented in Table 1. All were RCTs mostly conducted in the USA. In the studies of Dike et al. (27) and Kresz et al. (24) upper GI endoscopies were carried out. The sample size of the studies varied from 20 to 91 patients per arm. The definition of pediatric patients varied in the studies with one trial (27) including patients $<21$ years of age while the remaining including patients $<18$ years of age. Abdominal pain as an indication for the procedure was not significantly different between the $\mathrm{CO}_{2}$ and air groups in any trial. The duration of the procedure was reported by three studies $(23,24,26)$ with no statistically significant differences between the two groups.

The risk of bias analysis of included studies is presented in Figure 2. All trials had a low risk of bias for randomization, allocation concealment, and blinding of participants. In the study of Kresz et al. (24), the operators were no blinded. Three trials (24, $26,27)$ mentioned blinding of outcomes assessment. Complete outcome data (abdominal distention) was not reported in two studies $(23,27)$ and hence were marked with a high risk of bias for reporting bias.

\section{Outcomes}

Pain after the procedure was assessed by all included studies. All trials reported the number of patients experiencing pain after the procedure as a dichotomous variable. Pooled analysis of data from 226 patients in the $\mathrm{CO}_{2}$ group and 224 patients in the air group revealed that patients receiving $\mathrm{CO}_{2}$ insufflation were at a lower odds of experiencing postoperative pain as compared to those undergoing the procedure with air (OR: $0.40 ; 95 \%$ CI: $0.19,0.87 ; I^{2}=62 \% ; p=0.02$; Figure 3$)$. The results of the sensitivity analysis are presented in Table 2. Except for the trial of Dharmaraj et al. (26), on the exclusion of any of the remaining studies, the results were non-significant. Since pain scores as mean and standard deviation were not coherently reported by the included trials, a meta-analysis for the same could not be carried out. Similarly, data on abdominal distention and elevated $\mathrm{EtCO}_{2}$ were not sufficiently reported and the results were analyzed qualitatively.

Table 3 presents a descriptive analysis of all outcomes in the included studies. For pain scores, only Dike et al. (27) and Kresz et al. (24) did not report a statistically significant difference between the $\mathrm{CO}_{2}$ and air groups. However, Dike et al. (27) reported a significantly lower number of patients experiencing no pain, and Kresz et al. (24) found overall lower pain scores in the $\mathrm{CO}_{2}$ group. Four of the five trials evaluated

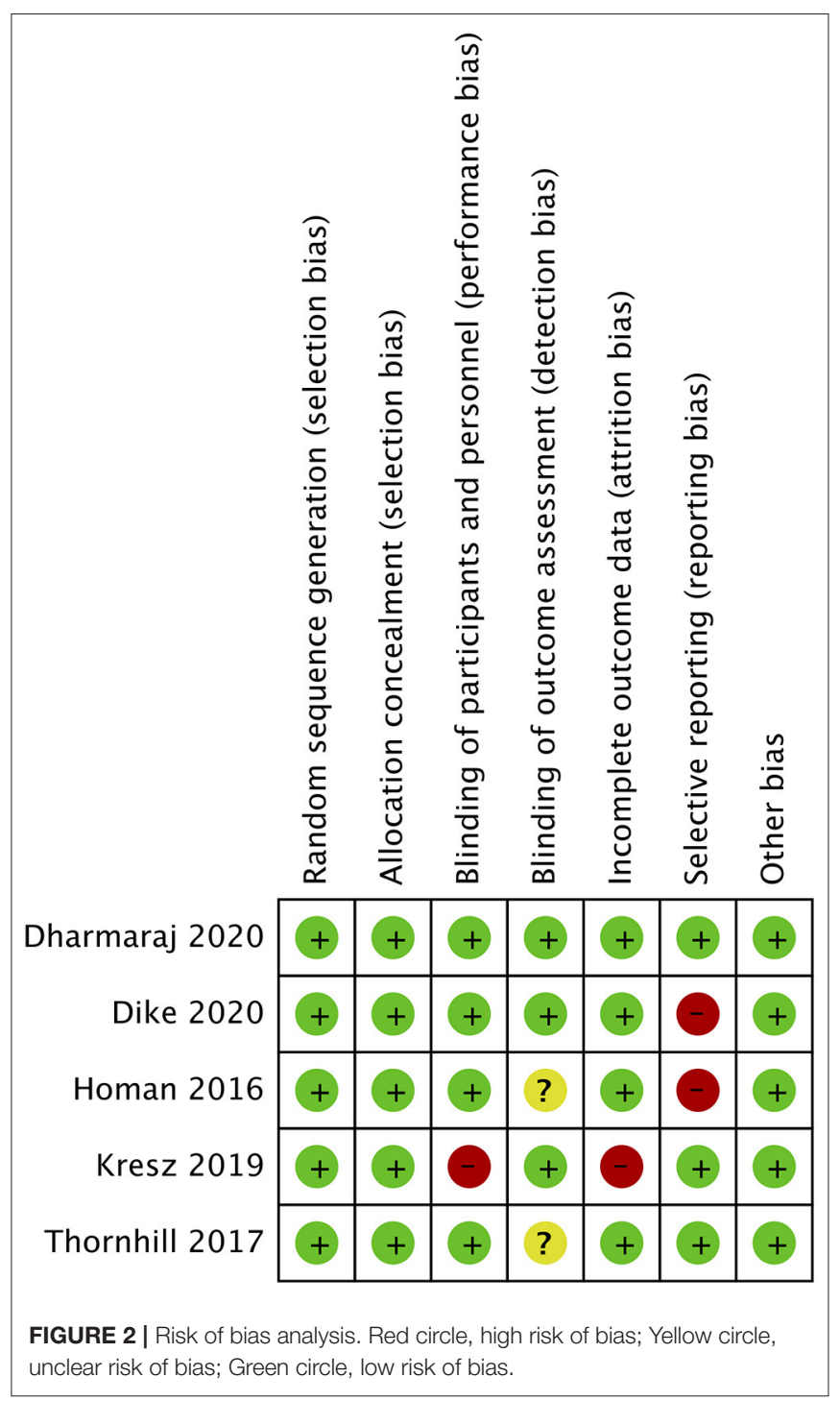

the degree of abdominal distention in study groups. Dharmaraj et al. (26) reported significant distention in the air group while the remaining trials $(23,24,27)$ reported no differences between the groups. Maximum $\mathrm{EtCO}_{2}$ levels were significantly higher in the $\mathrm{CO}_{2}$ group in two trials $(26,27)$. However, none of the studies reported any pulmonary complications with elevated $\mathrm{CO}_{2}$ in the study group. Bloating was measured in two trials $(24,27)$ and both reported significantly less bloating in the $\mathrm{CO}_{2}$ group.

\section{DISCUSSION}

The results of our review indicate that the use of $\mathrm{CO}_{2}$ insufflation in pediatric GI endoscopy procedures may result in a lower incidence of post-procedural pain. Descriptive analysis indicates that there is no difference in abdominal distention after the procedure with the use of either $\mathrm{CO}_{2}$ or air. Bloating may be less with $\mathrm{CO}_{2}$. Further, there may not be any increase in complications with $\mathrm{CO}_{2}$ use. 


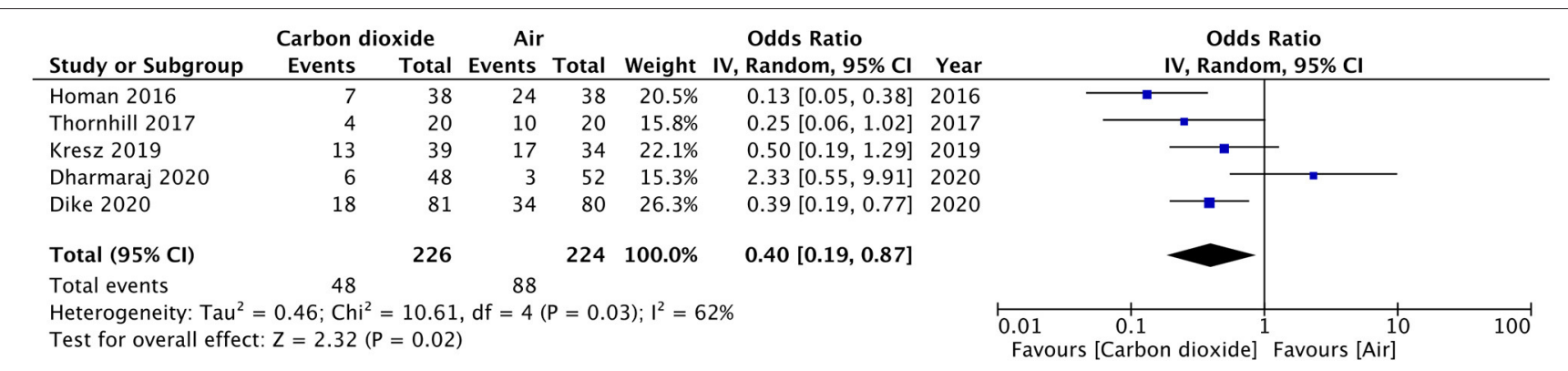

FIGURE 3 | Meta-analysis of incidence of pain after pediatric $\mathrm{Gl}$ endoscopy with $\mathrm{CO}_{2}$ and air.

TABLE 2 | Results of sensitivity analysis.

\begin{tabular}{ll}
\hline Excluded study & Effect size \\
\hline Dike et al. (27) & OR: $0.42 ; 95 \% \mathrm{Cl}: 0.14,1.28 ; \imath^{2}=72 \% ; p=0.13$ \\
Dharmaraj et al. (26) & OR: $0.31 ; 95 \% \mathrm{Cl}: 0.18,0.54 ; \imath^{2}=25 \% ; p<0.0001$ \\
Kresz et al. (24) & OR: $0.39 ; 95 \% \mathrm{Cl}: 0.14,1.07 ; \imath^{2}=71 \% ; p=0.07$ \\
Thornhill et al. (25) & OR: $0.45 ; 95 \% \mathrm{Cl}: 0.18,1.11 ; \imath^{2}=71 \% ; p=0.08$ \\
Homan et al. (23) & OR: $0.53 ; 95 \% \mathrm{Cl}: 0.25,1.10 ; \imath^{2}=48 \% ; p=0.09$
\end{tabular}

OR, odds ratio; $\mathrm{Cl}$ confidence interval.

One of the important differences between adult and pediatric upper GI endoscopies and colonoscopies is the use of deep sedation during pediatric procedures. According to Thakkar et al. $(28,29), 54 \%$ of pediatric EGDs are carried out under general anesthesia (GA) while $46 \%$ of the procedures take place under intravenous sedation. On the other hand, approximately half of colonoscopies in children are carried out under GA. On account of the effects of anesthesia, pain during and after the procedure may not be appreciated well enough by the treating physician in the case of pediatric patients (25). However, studies carried out in adult patients have demonstrated that pain is significantly reduced with the use of $\mathrm{CO}_{2}$ insufflation during colonoscopy in sedated and non-sedated patients. Bretthauer et al. (30) in a study of 103 colonoscopy patients sedated with midazolam and pethidine reported a significant decrease in pain scores with $\mathrm{CO}_{2}$ insufflation at 1 and $3 \mathrm{~h}$ after the procedure. Similarly, Seo et al. (31) in a double-blind RCT on sedated patients undergoing colonoscopy have also reported a higher number of pain-free patients with $\mathrm{CO}_{2}$ as compared to air insufflation (91.6 vs. $76.1 \%)$. Another RCT has shown reduced pain scores with $\mathrm{CO}_{2}$ in non-sedated patients undergoing colonoscopy (32). The encouraging results in adults have prompted the use of $\mathrm{CO}_{2}$ in pediatric endoscopies as well, but, as seen in our review only five RCTs have been published to date. The results of our study concur with the outcomes reported in adult patients. On pooled analysis of data from 450 patients, our results indicated that $\mathrm{CO}_{2}$ insufflation can reduce the odds of postoperative pain by around $60 \%$ (95\% CI: 13-81\%). However, the strength of the evidence is reduced with the wide confidence intervals and the instability of the results on a sensitivity analysis. On the sequential exclusion of four of the five trials, the results were non-significant indicating no benefit of $\mathrm{CO}_{2}$ over air. This can be partly attributed to the heterogeneity in the included studies for the different age groups, different sedation protocols as well as the different scales used to evaluate pain in pediatric patients. It is known that pain scores in children can be very subjective and can depend upon the child's confidence to adequately deal with the pain (33). Furthermore, research also indicates that pain may not be a significant issue after GI endoscopy. Allen et al. (34) in a study of 227 patients have demonstrated that $<50 \%$ of patients undergoing colonoscopy complain of pain and only $1 / 10$ th of all patients need an analgesic. Therefore, in the absence of pain, the utility of $\mathrm{CO}_{2}$ insufflation as compared to air may be questioned.

Pain-related to endoscopic procedures have been attributed to the overdistention of the bowel. Since $\mathrm{CO}_{2}$ undergoes rapid absorption via the intestinal mucosa and is quickly excreted via the respiratory tract, the use of this gas during endoscopic procedures can reduce post-operative abdominal distention $(5,6)$. Therefore, post-procedural abdominal girth can be an important surrogate marker in assessing the efficacy of $\mathrm{CO}_{2}$ insufflation in endoscopic procedures. Lack of adequate data prevented us from quantitatively examining post-procedural abdominal distention in our analysis. However, qualitative analysis revealed that only one trial reported significantly greater abdominal distention with air insufflation. It is important to note that abdominal girth was measured using tape in all studies. While adult studies have demonstrated lower abdominal distention using tape measurements, the technique is not considered to be accurate (31). Precise outcomes can only be assessed by radiological techniques but are limited due to ethical issues (23). Patient-reported bloating, though a subjective outcome, was reported to be lower with $\mathrm{CO}_{2}$ insufflation in two trials.

An important safety concern with the use of $\mathrm{CO}_{2}$ is the risk of systemic hypercarbia leading to cardiac or respiratory compromise (35). The rapid absorption of $\mathrm{CO}_{2}$ can potentially strain the respiratory system during its excretion. This may be further compounded by the use of sedation in pediatric patients leading to inadequate respiratory compensation $(25,36)$. Several RCTs in adults have therefore excluded patients with cardiac and respiratory illnesses, opioid users, and patients with high baseline pCO2 levels while assessing the efficacy of $\mathrm{CO}_{2}$ insufflation in GI endoscopies $(32,37)$. However, recent evidence shows that $\mathrm{CO}_{2}$ insufflation can be safely used in high-risk patients like 
TABLE 3 | Descriptive analysis of outcomes in included studies.

\begin{tabular}{|c|c|c|}
\hline References & Outcome & Results \\
\hline \multirow[t]{8}{*}{ Dike et al. (27) } & Pain on FLACC & No statistical significant differences between the two groups in recovery \\
\hline & Pain on GPPP & No statistical significant differences between the two groups in recovery and at home \\
\hline & Pain on faces scale & Significantly lower number of patients with no pain in recovery in the $\mathrm{CO}_{2}$ group \\
\hline & Abdominal distention & $\begin{array}{l}\text { No statistical significant differences between the two groups at the end of the procedure, at discharge } \\
\text { from recovery and at home }\end{array}$ \\
\hline & Bloating & Significantly less in the $\mathrm{CO}_{2}$ group \\
\hline & Flatulence & Significantly less in the $\mathrm{CO}_{2}$ group \\
\hline & Belching & Significantly more in the $\mathrm{CO}_{2}$ group \\
\hline & Elevated $\mathrm{EtCO}_{2}$ & $\begin{array}{l}\text { Significantly higher number of episodes of transient hypercarbia ( }>60 \mathrm{mmHg},<1 \mathrm{~min} \text { ) in the } \mathrm{CO}_{2} \text { group. } \\
\text { Two patients in the } \mathrm{CO}_{2} \text { group experienced sustained hypercarbia ( }>60 \mathrm{mmHg}, \geq 5 \mathrm{~min} \text { ) }\end{array}$ \\
\hline \multirow[t]{5}{*}{ Dharmaraj et al. (26) } & Pain & Significantly lower pain in patients in the $\mathrm{CO}_{2}$ group \\
\hline & Pain medications in recovery & No statistical significant differences between the two groups \\
\hline & Abdominal distention & Significantly increased abdominal distention at the end of the procedure in the air group \\
\hline & Elevated $\mathrm{EtCO}_{2}$ & $\begin{array}{l}\text { Maximum } \mathrm{EtCO}_{2} \text { values during the procedure significantly higher in the } \mathrm{CO}_{2} \text { group. No adverse events } \\
\text { related to elevated } \mathrm{EtCO}_{2} \text { noted up to } 72 \mathrm{~h} \text { after the procedure }\end{array}$ \\
\hline & Time to discharge & No statistical significant differences between the two groups \\
\hline \multirow[t]{6}{*}{ Kresz et al. (24) } & Pain & Lower pain scores in the $\mathrm{CO}_{2}$ group at $15 \mathrm{~min}, 1,3$, and $24 \mathrm{~h}$ but results were not statistically significant \\
\hline & Additional narcotics during procedure & Significantly higher number of patients required narcotics in the air group \\
\hline & Abdominal distention & No statistical significant differences between the two groups at $5 \mathrm{~min}$ at $60 \mathrm{~min}$ after the procedure \\
\hline & Bloating & Significantly less in the $\mathrm{CO}_{2}$ group \\
\hline & Elevated $\mathrm{PtCO}_{2}$ & No statistical significant differences between the two groups \\
\hline & & No statistical significant differences between the two groups \\
\hline \multirow[t]{2}{*}{ Thornhill et al. (25) } & Pain & Significantly lower pain in patients in the $\mathrm{CO}_{2}$ group at $1 \mathrm{~h}$ but not at 6 and $24 \mathrm{~h}$ \\
\hline & Elevated $\mathrm{EtCO}_{2}$ & $\begin{array}{l}\text { No statistical significant differences between the two groups at cecal intubation, end of procedure and } \\
10 \text { min after procedure. No pulmonary complications in either groups }\end{array}$ \\
\hline \multirow[t]{2}{*}{ Homan et al. (23) } & Pain & Significantly lower pain in patients in the $\mathrm{CO}_{2}$ group at 2 and $4 \mathrm{~h}$ \\
\hline & Abdominal distention & No statistical significant differences between the two groups at $10 \mathrm{~min}, 2$ and $4 \mathrm{~h}$ after colonoscopy \\
\hline
\end{tabular}

EtCO $\mathrm{C}_{2}$, end tidal $\mathrm{CO}_{2} ; \mathrm{PtCO}$, percutaneous $\mathrm{CO}_{2} ; \mathrm{FLACC}$, face, legs, activity, cry, and ability to be consoled; GPPP, global parent perception of pain.

those with obstructive ventilatory disturbance (38). Studies on healthy sedated adults have also shown $\mathrm{CO}_{2}$ insufflation to be safe $(30,31)$. In line with these studies, no safety concerns were reported with the use of $\mathrm{CO}_{2}$ in any of the included trials of our review. The significantly higher number of transient hypercarbia episodes in the study of Dike et al. (27) were all seen with upper GI endoscopies. The authors reported that these episodes were a result of belching of $\mathrm{CO}_{2}$ during EGD which were detected in exhaled breath. None of the trials reported abandoning the procedure due to high $\mathrm{EtCO}_{2}$ levels in any patient.

Our review has some limitations. Firstly, only five studies were available for inclusion. The sample size of three trials was $<50$ patients per group. Secondly, there were concerns of bias due to inadequate blinding, attrition, and selective reporting in some of the trials. This could have skewed outcomes in the review. Thirdly, there was inter-study heterogeneity amongst the included studies as mentioned earlier. Fourthly, lack of data, and standard reporting precluded us from assessing all outcomes via a meta-analysis. Pain was assessed only as a dichotomous variable and mean differences of pain scores at various time intervals could not be assessed.

Nevertheless, our study is the first review evaluating the efficacy of $\mathrm{CO}_{2}$ insufflation vs. air in pediatric GI endoscopies. A comprehensive literature search was conducted to extract all eligible studies. A descriptive analysis of all outcomes reported by the trials was performed to present complete evidence to the readers. A sensitivity analysis was also conducted to assess the influence of each study on the pooled effect size.

To conclude, our study indicates that the incidence of pain may be reduced with the use of $\mathrm{CO}_{2}$ insufflation in pediatric GI endoscopies without a significant risk of adverse events. However, current evidence is from a limited number of trials and not strong to recommend a routine of $\mathrm{CO}_{2}$ in pediatric gastroenterology practice. Further high-quality RCTs with a large sample size and evaluating standard outcomes on a common scale are required to supplement current evidence.

\section{DATA AVAILABILITY STATEMENT}

Publicly available datasets were analyzed in this study. This data can be found at: PubMed, Embase, Scopus, and CENTRAL.

\section{AUTHOR CONTRIBUTIONS}

CJ conceived and designed the study. XL and $\mathrm{PH}$ were involved in literature search and data collection. CJ and XL analyzed the data. CJ wrote the paper. $\mathrm{PH}$ reviewed and edited the manuscript. All authors read and approved the final manuscript. 


\section{REFERENCES}

1. Wang WL, Wu ZH, Sun Q, Wei JF, Chen XF, Zhou DK, et al. Metaanalysis: the use of carbon dioxide insufflation vs. room air insufflation for gastrointestinal endoscopy. Aliment Pharmacol Ther. (2012) 35:1145-54. doi: 10.1111/j.1365-2036.2012.05078.x

2. Kim SY, Chung JW, Park DK, Kwon KA, Kim KO, Kim YJ, et al. Comparison of carbon dioxide and air insufflation during consecutive EGD and colonoscopy in moderate-sedation patients: a prospective, doubleblind, randomized controlled trial. Gastrointest Endosc. (2017) 85:1255-62. doi: $10.1016 /$ j.gie.2016.10.042

3. Feisthammel J, Trung KV, Hollenbach M, Mössner J, Hoffmeister A. Is $\mathrm{CO}_{2}$ insufflation an amelioration of routine colonoscopy? Minerva Gastroenterol Dietol. (2018) 64:193-200. doi: 10.23736/S1121-421X.18. 02478-9

4. Becker GL. The prevention or gas explosions in the large bowel during electrosurgery. Surg Gynecol Obstet. (1953) 97:463-7.

5. Geyer M, Guller U, Beglinger C. Carbon dioxide insufflation in routine colonoscopy is safe and more comfortable: Results of a randomized controlled double-blinded trial. Diagn Ther Endosc. (2011) 2011:378906. doi: $10.1155 / 2011 / 378906$

6. Bretthauer M, Hoff GS, Thiis-Evensen E, Huppertz-Hauss G, Skovlund E. Air and carbon dioxide volumes insufflated during colonoscopy. Gastrointest Endosc. (2003) 58:203-6. doi: 10.1067/mge.2003.340

7. Memon MA, Memon B, Yunus RM, Khan S. Carbon dioxide versus air insufflation for elective colonoscopy: a meta-analysis and systematic review of randomized controlled trials. Surg Laparosc Endosc Percutaneous Tech. (2016) 26:102-16. doi: 10.1097/SLE.0000000000 000243

8. Rogers AC, Van De Hoef D, Sahebally SM, Winter DC. A meta-analysis of carbon dioxide versus room air insufflation on patient comfort and key performance indicators at colonoscopy. Int J Colorectal Dis. (2020) 35:455-64. doi: 10.1007/s00384-019-03470-4

9. Aquino J, Bernardo W, de Moura D, Morita F, Rocha R, Minata M, et al. Carbon dioxide versus air insufflation enteroscopy: a systematic review and meta-analysis based on randomized controlled trials. Endosc Int Open. (2018) 06:E637-45. doi: 10.1055/a-0574-2357

10. Oliva S, Thomson M, De Ridder L, Martín-De-Carpi J, Van Biervliet S, Braegger $C$, et al. Endoscopy in pediatric inflammatory bowel disease: a position paper on behalf of the Porto IBD Group of the European Society for Pediatric Gastroenterology, Hepatology and Nutrition. $J$ Pediatr Gastroenterol Nutr. (2018) 67:414-30. doi: 10.1097/MPG.0000000000 002092

11. Nardo G Di, Oliva S, Barbato M, Aloi M, Midulla F, Roggini M, et al. Argon plasma coagulator in a 2-month-old child with tracheoesophageal fistula. Surg Endosc. (2012) 26:2678-80. doi: 10.1007/s00464-0122214-7

12. Borrelli O, Pescarin M, Saliakellis E, Tambucci R, Quitadamo P, Valitutti F, et al. Sequential incremental doses of bisacodyl increase the diagnostic accuracy of colonic manometry. Neurogastroenterol Motil. (2016) 28:1747-55. doi: $10.1111 / \mathrm{nmo} .12876$

13. Tringali A, Thomson M, Dumonceau JM, Tavares M, Tabbers MM, Furlano R, et al. Pediatric gastrointestinal endoscopy: European Society of Gastrointestinal Endoscopy (ESGE) and European Society for Paediatric Gastroenterology Hepatology and Nutrition (ESPGHAN) Guideline Executive summary. Endoscopy. (2017) 49:83-91. doi: 10.1055/s-0042111002

14. Silva S, Silva C, Espinheira MDC, Pais IP, Trindade E, Dias JA. Diagnostic yield of endoscopic procedures in children: experience of a Portuguese center. $G E$ Port J Gastroenterol. (2020) 27:404-9. doi: 10.1159/000507207

15. Arsiè E, Cantù P, Penagini R. The role of endoscopy in eosinophilic esophagitis: from diagnosis to therapy. Minerva Gastroenterol Dietol. (2020). doi: 10.23736/S1121-421X.20.02786-5

16. Trovato CM, Montuori M, Anania C, Barbato M, Vestri AR, Guida S, et al. Are ESPGHAN "biopsy-sparing" guidelines for celiac disease also suitable for asymptomatic patients? Am J Gastroenterol. (2015) 110:1485-9. doi: 10.1038/ajg.2015.285
17. Passos M, Ribeiro I, de Moura D, Korkischko N, Silva G, Franzini T, et al. Efficacy and safety of carbon dioxide insufflation versus air insufflation during endoscopic retrograde cholangiopancreatography in randomized controlled trials: a systematic review and meta-analysis. Endosc Int Open. (2019) 7:E48797. doi: 10.1055/a-0854-3739

18. Takada J, Araki H, Mizutani T, Ozawa N, Sugiyama T, Kubota M, et al. Safety of carbon dioxide insufflation during endoscopic submucosal dissection for esophageal squamous cell carcinoma. Dig Dis. (2019) 37:93-9. doi: $10.1159 / 000492870$

19. Moher D, Liberati A, Tetzlaff J, Altman DG, PRISMA Group. Preferred reporting items for systematic reviews and meta-analyses: the PRISMA statement. PLoS Med. (2009) 6:e1000097. doi: 10.1371/journal.pmed.1000097

20. Higgins J, Thomas J, Chandler J, Cumpston M, Li T, Page M, et al. Cochrane Handbook for Systematic Reviews of Interventions. Version 6. Chichester: John Wiley \& Sons (2019). doi: 10.1002/9781119536604

21. Nakayama Y, Abe N, Kusakari M, Kato S, Hidaka N. Sa1667 the safety and effectiveness of carbon dioxide insufflation during colonoscopy in sedated pediatric patients with inflammatory bowel disease. Gastrointest Endosc. (2015) 81:AB301. doi: 10.1016/j.gie.2015.03.1427

22. Ibarguen-Secchia E. Use of $\mathrm{CO}_{2}$ for insufflation during colonoscopy in children. Am J Gastroenterol. (2007) 102:S548-9. doi: 10.14309/00000434-200709002-01177

23. Homan M, Mahkovic D, Orel R, Mamula P. Randomized, double-blind trial of $\mathrm{CO} 2$ versus air insufflation in children undergoing colonoscopy. Gastrointest Endosc. (2016) 83:993-7. doi: 10.1016/j.gie.2015.08.073

24. Kresz A, Mayer B, Zernickel M, Posovszky C. Carbon dioxide versus room air for colonoscopy in deeply sedated pediatric patients: a randomized controlled trial. Endosc Int Open. (2019) 7:E290-7. doi: 10.1055/a-0806-7060

25. Thornhill C, Navarro F, Alrazzak BA, Hashmi SS, DebRoy AN, Rhoads $J M$, et al. Insufflation with carbon dioxide during pediatric colonoscopy for control of postprocedure pain. J Clin Gastroenterol. (2018) 52:715-20. doi: 10.1097/MCG.0000000000000910

26. Dharmaraj R, Dunn R, Fritz J, Dasgupta M, Simpson P, Cabrera J, et al. Efficacy and safety of carbon dioxide versus air insufflation for colonoscopy in deeply sedated pediatric patients. J Pediatr Gastroenterol Nutr. (2020) 71:34-9. doi: 10.1097/MPG.0000000000002650

27. Dike CR, Rahhal R, Bishop WP. Is carbon dioxide insufflation during endoscopy in children as safe and as effective as we think? J Pediatr Gastroenterol Nutr. (2020) 71:211-5. doi: 10.1097/MPG.0000000000002724

28. Thakkar K, El-Serag HB, Mattek N, Gilger MA. Complications of pediatric EGD: a 4-year experience in PEDS-CORI. Gastrointest Endosc. (2007) 65:21321. doi: 10.1016/j.gie.2006.03.015

29. Thakkar K, Holub JL, Gilger MA, Shub MD, McOmber M, Tsou $\mathrm{M}$, et al. Quality indicators for pediatric colonoscopy: results from a multicenter consortium. Gastrointest Endosc. (2016) 83:533-41. doi: 10.1016/j.gie.2015.06.028

30. Bretthauer M, Lynge AB, Thiis-Evensen E, Hoff G, Fausa O, Aabakken L. Carbon dioxide insufflation in colonoscopy: Safe and effective in sedated patients. Endoscopy. (2005) 37:706-9. doi: 10.1055/s-2005-870154

31. Seo EH, Kim TO, Park MJ, Kim HJ, Shin BC, Woo JG, et al. The efficacy and safety of carbon dioxide insufflation during colonoscopy with consecutive esophagogastroduodenoscopy in moderately sedated outpatients: a randomized, double-blind, controlled trial. J Clin Gastroenterol. (2013) 47:e45-9. doi: 10.1097/MCG.0b013e31825c023a

32. Bretthauer M, Thiis-Evensen E, Huppertz-Hauss G, Gisselsson L, Grotmol T, Skovlund E, et al. NORCCAP (Norwegian colorectal cancer prevention): a randomised trial to assess the safety and efficacy of carbon dioxide versus air insufflation in colonoscopy. Gut. (2002) 50:604-7. doi: 10.1136/gut.50.5.604

33. Stahlschmidt L, Hübner-Möhler B, Dogan M, Wager J. Pain self-efficacy measures for children and adolescents: a systematic review. J Pediatr Psychol. (2019) 44:530-41. doi: 10.1093/jpepsy/jsz002

34. Allen P, Shaw E, Jong A, Behrens H, Skinner I. Severity and duration of pain after colonoscopy and gastroscopy: a cohort study. J Clin Nurs. (2015) 24:1895-903. doi: 10.1111/jocn.12817

35. Price HL. Effects of carbon dioxide on the cardiovascular system. Anesthesiology. (1960) 21:652-63. doi: 10.1097/00000542-19601100000009 
36. Lord AC, Riss S. Is the type of insufflation a key issue in gastrointestinal endoscopy? World J Gastroenterol. (2014) 20:2193-9. doi: 10.3748/wjg.v20.i9.2193

37. Yamano HO, Yoshikawa K, Kimura T, Yamamoto E, Harada E, Kudou T, et al. Carbon dioxide insufflation for colonoscopy: evaluation of gas volume, abdominal pain, examination time and transcutaneous partial $\mathrm{CO} 2$ pressure. J Gastroenterol. (2010) 45:1235-40. doi: 10.1007/s00535-010-0286-5

38. Yoshida M, Imai K, Hotta K, Yamaguchi Y, Tanaka M, Kakushima N, et al. Carbon dioxide insufflation during colorectal endoscopic submucosal dissection for patients with obstructive ventilatory disturbance. Int $J$ Colorectal Dis. (2014) 29:365-71. doi: 10.1007/s00384-013-1806-6
Conflict of Interest: The authors declare that the research was conducted in the absence of any commercial or financial relationships that could be construed as a potential conflict of interest.

Copyright (c) $2021 \mathrm{Ji}$, Liu and Huang. This is an open-access article distributed under the terms of the Creative Commons Attribution License (CC BY). The use, distribution or reproduction in other forums is permitted, provided the original author(s) and the copyright owner(s) are credited and that the original publication in this journal is cited, in accordance with accepted academic practice. No use, distribution or reproduction is permitted which does not comply with these terms. 